\title{
The Prognostic Impact of High On-Treatment Platelet Reactivity with Aspirin or ADP Receptor Antagonists: Systematic Review and Meta-Analysis
}

\author{
Fabrizio D'Ascenzo, ${ }^{1}$ Umberto Barbero, ${ }^{1}$ Marta Bisi, ${ }^{1}$ Claudio Moretti, ${ }^{1}$ Pierluigi Omedè, \\ Enrico Cerrato, ${ }^{1}$ Giorgio Quadri, ${ }^{1}$ Federico Conrotto, ${ }^{1}$ Giuseppe Biondi Zoccai, ${ }^{2}$ \\ James J. DiNicolantonio, ${ }^{3}$ Mauro Gasparini, ${ }^{4}$ Sripal Bangalore, ${ }^{5}$ and Fiorenzo Gaita ${ }^{1}$ \\ ${ }^{1}$ Department of Internal Medicine, Division of Cardiology, Città Della Salute e Della Scienza, Turin, Italy \\ ${ }^{2}$ Department of Medico-Surgical Sciences and Biotechnologies, Sapienza University of Rome, Latina, Italy \\ ${ }^{3}$ Mid America Heart Institute at Saint Luke's Hospital, Kansas City, MO, USA \\ ${ }^{4}$ Politecnico of Turin, Turin, Italy \\ ${ }^{5}$ New York University School of Medicine, New York, NY, USA \\ Correspondence should be addressed to Fabrizio D’Ascenzo; fabrizio.dascenzo@gmail.com
}

Received 15 February 2014; Revised 26 June 2014; Accepted 26 June 2014; Published 13 October 2014

Academic Editor: Ahmed Abdel-Latif

Copyright (C) 2014 Fabrizio D’Ascenzo et al. This is an open access article distributed under the Creative Commons Attribution License, which permits unrestricted use, distribution, and reproduction in any medium, provided the original work is properly cited.

Objective. Negative results of recent randomized clinical trials testing the hypothesis of target therapy for patients with high ontreatment platelet reactivity (HOPR) have questioned its independent impact on clinical outcomes. 26 studies with 28.178 patients were included, with a median age of 66.8 (64-68) and 22.7\% (22.4-27.8), of female gender. After a median follow-up of 1 year (0.1-1), cardiac adverse events occurred in $8.3 \%$ (3-11; all results are reported as median and interquartile range) of patients. Pooling all studies together, on-treatment platelet reactivity significantly increased the risk of adverse events (OR 1.33 [1.09, 1.64], $I^{2}=0 \%$ ). However, a sensitivity analysis showed that HOPR did not increase the risk of adverse events for patients with ACS, AMI, or stable angina as well as patients resistant to aspirin, ADP antagonists, or both. For all studies, publication bias was formally evident; after adjusting for this, HOPR did not significantly increase adverse cardiac events (OR 1.1: 0.89-1.22, $I^{2}$ 0\%). Conclusions. After adjusting for clinical confounders (like risk factors and clinical presentation) and for relevant publication bias, HOPR was not an independent prognostic indicator in unselected patients with both stable and unstable coronary disease for an adverse cardiac event. The clinical importance of HOPR for high-risk populations remains to be assessed.

\section{Introduction}

Aspirin and ADP receptor antagonists represent an unquestionable strategy for patients undergoing percutaneous coronary intervention (PCI), both for stable and unstable coronary disease [1]. High on-treatment platelet reactivity (HOPR), variously defined and analyzed, has been reported in up to $30 \%$ of these patients [2] and has been linked to adverse cardiac events at follow-up [3-6].

Due to the high prevalence of HOPR and the assumption that HOPR increases the risk of adverse cardiac events, randomized clinical trials were performed to test the safety and efficacy of a tailored strategy (defined as an increase in dose or a switch to another ADP receptor antagonist) in patients undergoing PCI. When appraised separately, most of these studies were negative, without achieving the expected reduction in recurrent thrombotic events [7-9].

Prognostic impact of HOPR was assessed by at least two meta-analyses, although limited from methodological flaws $[3,4]$, due to lack of adjustement for baseline differences in burden of traditional risk factors and clinical presentation, which may explain themselves the increased risk of adverse cardiac events in selected patients. These two studies, however, have not tested the independent clinical effect of 
inadequate platelet inhibition on outcomes; moreover they evaluated patients with different risk profiles (ACS and stable angina) and different treatments (aspirin together with ADP antagonists or periprocedural glycoprotein inhibitors [10, 11]).

Randomisation of patients to HOPR and non-HOPR groups is obviously not feasible; consequently a bias analysis may help to elucidate the impact of HOPR on clinical prognosis independently from cardiovascular risk factors and clinical presentations.

\section{Methods}

The recent Preferred Reporting Items for Systematic reviews and Meta-Analyses (PRISMA) amendment to the Quality of Reporting of Meta-analyses (QUOROM) statement, and recommendations from The Cochrane Collaboration and Meta-analysis of Observational Studies in Epidemiology (MOOSE) were followed during the development of the present systematic review [11-16].

2.1. Search Strategy and Study Selection. Pertinent articles were searched in Medline, Cochrane Library, Biomed Central, and Google Scholar in keeping with established methods with MESH strategy and with the following terms: (Prognosis/Broad[filter]) AND (platelet* AND (reactivity OR aggregation OR activation OR response* ${ }^{*}$ AND (death OR (myocardial AND infarction))). Three independent reviewers (Fabrizio D’Ascenzo, Umberto Barbero, and Marta Bisi) screened the retrieved citations via the title and/or abstract; divergences were resolved via consensus. If potentially pertinent, studies were then appraised as complete reports according to the following explicit selection criteria. Studies were included if (i) reporting more than 50 patients (ii) independent prognostic impact of HOPR evaluated through multivariate analysis, while exclusion criteria were (i) nonhuman setting, (ii) duplicate reporting (in which case the manuscript reporting the largest sample of patients was selected), and (iii) interventional studies.

2.2. Data Extraction, End Points, and Sensitivity Analysis. Three unblinded independent reviewers (Fabrizio D'Ascenzo, Umberto Barbero, and Marta Bisi) abstracted the following data on prespecified forms: authors, journal, year of publication, location of the study group, and baseline clinical and interventional features. Data extraction was conducted by mutual agreement and all potential disagreement was solved by consensus. Incidence of adverse cardiac events (all-cause mortality and cardiovascular mortality, nonfatal myocardial infarction and stroke, and revascularization and stent thrombosis) was the primary end point. Sensitivity analyses were performed appraising aspirin and ADP receptor antagonists separately. Similarly we appraise indications for PCI in stable and unstable disease (i.e., either unstable angina, ST and non-ST segment elevation myocardial infarction). Finally, we analyze all-cause death, stent thrombosis and major bleedings.

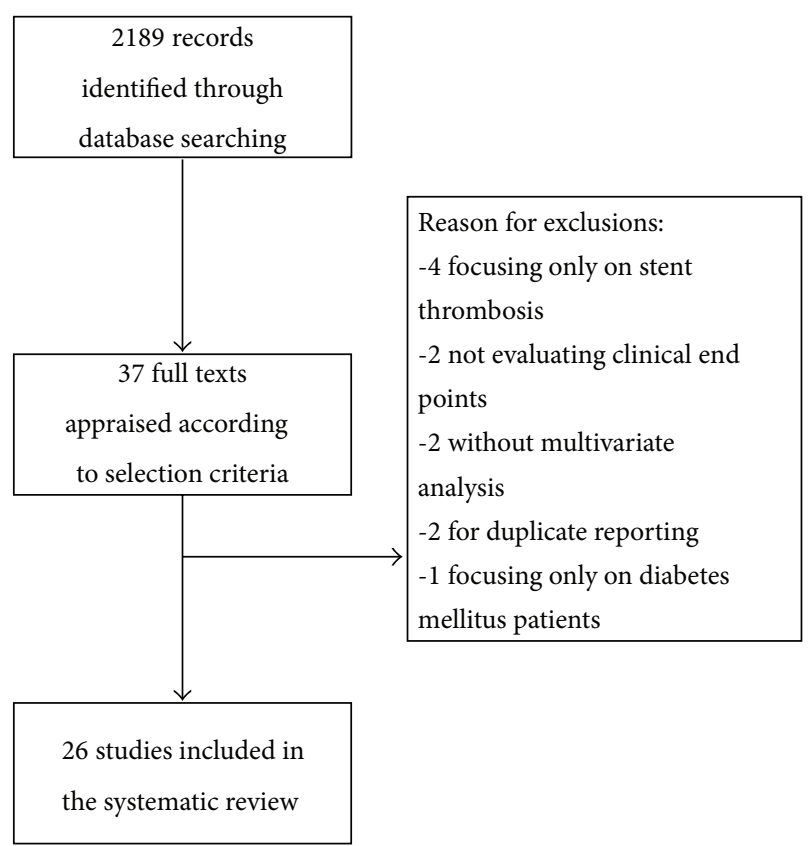

FIGURE 1: Review's profile.

2.3. Internal Validity and Quality Appraisal. Unblinded independent reviewers (Fabrizio D’Ascenzo, Umberto Barbero, and Marta Bisi) evaluated quality of included studies on prespecified forms. Modifying the MOOSE items to take into account the specific features of included studies [11], we separately abstracted and appraised study design, setting, and data source, as well as risk of analytical, selection, adjudication, detection, and attrition bias (expressed as low, moderate, or high risk of bias, as well as incomplete reporting leading to inability to ascertain the underlying risk of bias).

2.4. Data Analysis and Synthesis. Continuous variables are reported as mean (standard deviation) or median (interquartile). Categorical variables are expressed as $n / N$ (\%). Statistical pooling was performed according to a random-effect model with generic inverse-variance weighting, computing risk estimates with 95\% confidence intervals, using RevMan 5 (The Cochrane Collaboration, The Nordic Cochrane Centre, Copenhagen, Denmark), and Comprehensive Meta-Analysis. Metaregression analysis was performed to identify impact of length of follow-up on results. Small study bias was appraised by graphical inspection of funnel plots and formally through Begg and Mazumdar rank correlation, Egger's regression intercept, and Duval and Tweedie trim and fill [14].

\section{Results}

2189 records were identified through database searching, and 38 were appraised at text level and finally twenty-six studies (see Appendix) were included (Figure 1) including 28.178 patients. The median age was $66.8(64-68)$, with $22.7 \%$ (22.4-27.8) being female. Diabetes mellitus, hypertension, hyperlipidemia, and a history of previous MI were reported in 


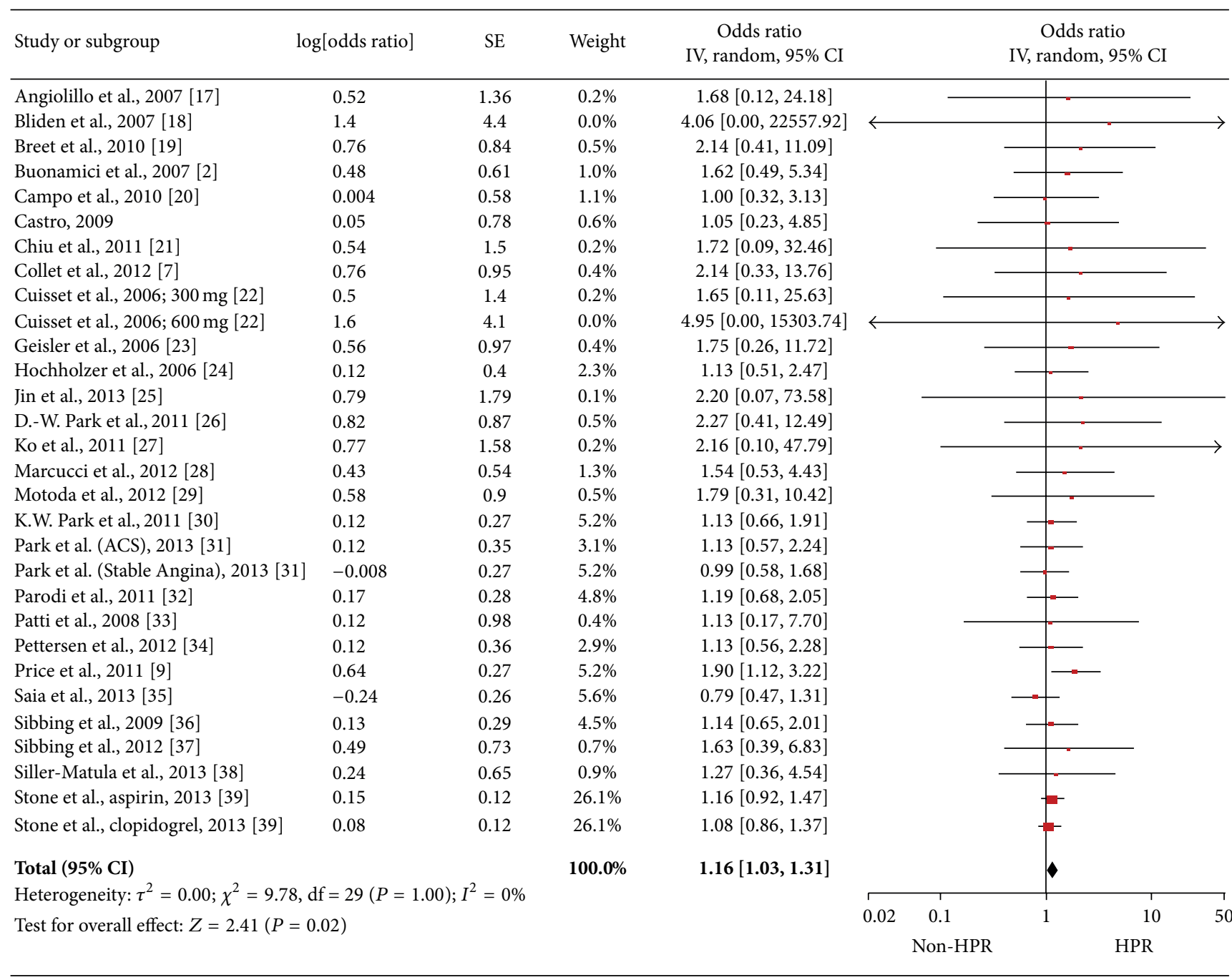

FIGURE 2: Pooled analysis of odds ratio for platelet reactivity for all studies [28.178 patients].

$29 \%$ (24.2-34), 84\% (58.9-89), 70\% (54.4-71), and 30\% (18$39)$, respectively. Stable angina was the admission diagnosis for $45 \%(37-100)$ of patients, ACS for $45 \%$ (33-100), and AMI for $12 \%(0-34)$. HOPR on aspirin was reported in $25 \%$ (22-26) of population, 29\% (25-37) for patients on ADP receptor antagonists, and 26\% (22-39) for both (Tables 1, 2, and 3 ). After a median follow-up of 1 year (0.1-1), adverse cardiac events occurred in $8.3 \%$ (3-11) of patients. Pooling all studies together, HOPR significantly increased the risk of adverse cardiac events (OR 1.33 [95\% CI: 1.09, 1.64], $I^{2} 0 \%$, Figure 2). At metaregression analysis, length of follow up did not influence these results (Beta-0.001, P 0.58). HOPR did not increase risk of death (OR $1.13[0.96,1.33], I^{2} 0 \%$ ), of stent thrombosis (OR $1.25[0.87,1.78], I^{2} 0 \%$ ), and of major bleedings $\left(1.20[0.93,1.56], I^{2} 21 \%\right.$, Figure 3$)$.

Sensitivity analysis for diagnosis showed that HOPR did not increase the risk of adverse cardiac events for patients with ACS $\left(1.06[0.79,1.43], I^{2}=0 \%\right)$, AMI $(0.95[0.61,1.46]$,
$\left.I^{2}=0 \%\right)$, or stable angina $\left(1.16[0.82,1.63], I^{2}=0 \%\right.$, Figure 4).

Sensitivity analysis according to type of antiplatelet medication indicated that neither was HOPR an independent predictor of adverse cardiac events, nor did this show if patients were resistant to aspirin, ADP antagonists (clopidogrel in all studies), or both $\left(1.16[0.93,1.45], I^{2}=0 \%\right.$; $1.09[0.93,1.28], I^{2}=0 \%$; and $1.26[0.70,2.27], I^{2}=0 \%$, Figure 5).

For all studies, publication bias was graphically evident (Figure 6) and formally assessed with Begg and Mazumdar rank correlation (with a positive Tau of 0.31 ) and with Egger's regression intercept (Intercept 0.42:0.11-0.69; $t$-value 2.81). After adjusting for this bias with Duval and Tweedie trim and fill, HOPR was not a significant prognostic indicator for all studies (OR 1.1 : 0.89-1.22, $I^{2} 0 \%$; trim and fill methods evaluate publication bias by evaluating number of "asymmetric" trials on the right side, removing and replacing them with 


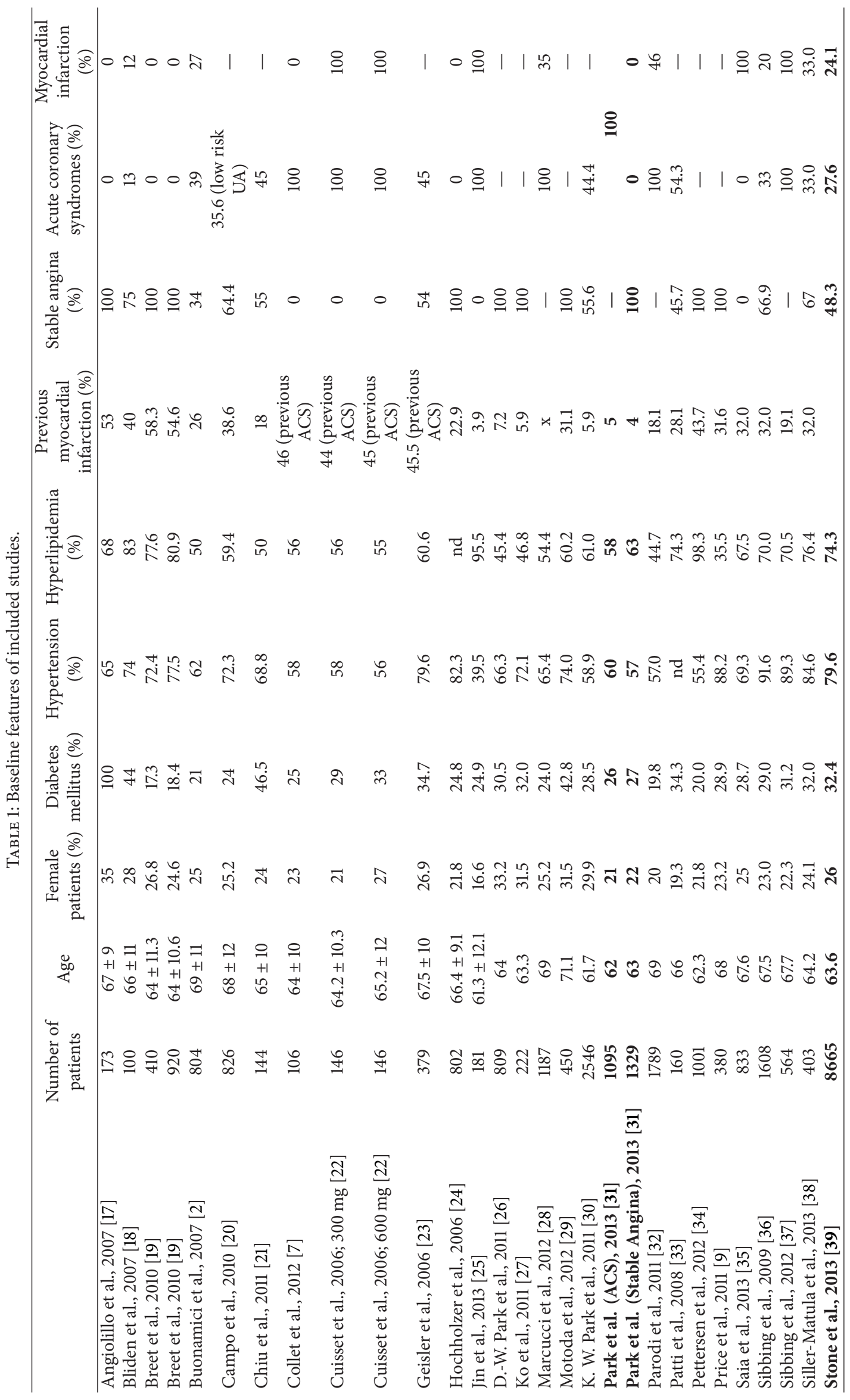




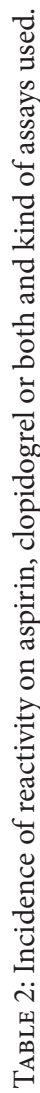

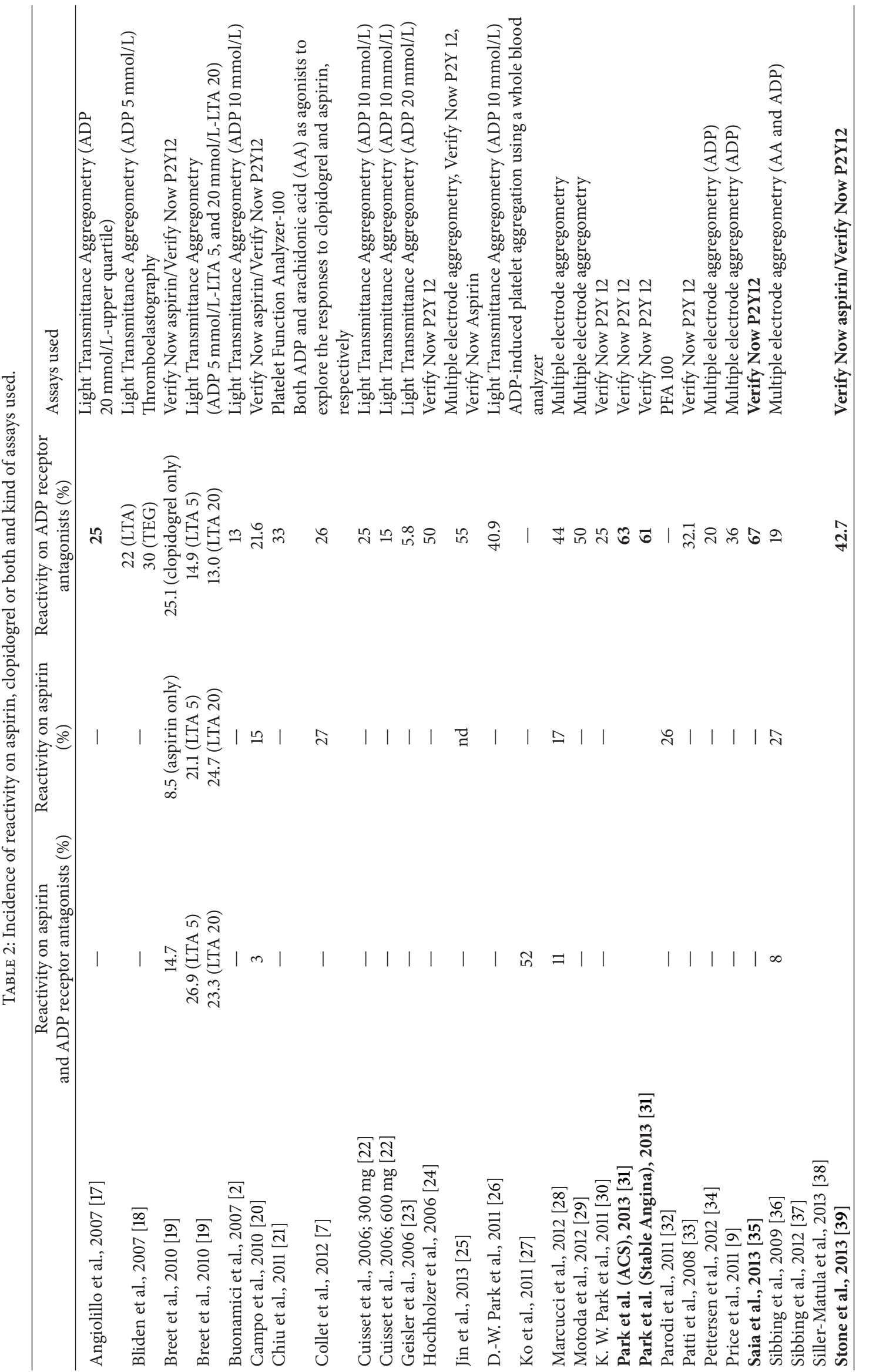


TABLE 3: Incidence and definition of outcome appraised in the multivariate model.

\begin{tabular}{|c|c|c|c|}
\hline & $\begin{array}{l}\text { Follow-up } \\
\text { (months) }\end{array}$ & Definition of outcome & $\begin{array}{c}\text { Incidence of } \\
\text { outcome }\end{array}$ \\
\hline \multirow{4}{*}{ Angiolillo et al., 2007 [17] } & \multirow{4}{*}{24} & \multirow{4}{*}{ Cardiovascular death, ACS, and stroke } & 15.2 1st quartile \\
\hline & & & 12.2 2nd quartile \\
\hline & & & 12.2 3rd quartile \\
\hline & & & 37.74 th quartile \\
\hline Bliden et al., 2007 [18] & $\begin{array}{l}1 \\
12\end{array}$ & $\begin{array}{l}\text { Death secondary to any cardiovascular cause, stroke, } \\
\text { myocardial infarction (ami), and target/nontarget vessel } \\
\text { revascularization }\end{array}$ & $\begin{array}{l}23 \text { (1 month FU) } \\
50 \text { (12 months FU) }\end{array}$ \\
\hline \multirow{8}{*}{ Breet et al., 2010 [19] } & \multirow{8}{*}{12} & \multirow{8}{*}{ All-cause death, nonfatal ami, stent thrombosis, and stroke } & LTA 511.3 (DHPR) \\
\hline & & & 8.8 (HAPR) \\
\hline & & & 10.9 (HCPR) \\
\hline & & & $4.1(\mathrm{NPR})$ \\
\hline & & & LTA 2010.7 (DHPR) \\
\hline & & & 9.6 (HAPR) \\
\hline & & & 11.7 (HCPR) \\
\hline & & & $4.2(\mathrm{NPR})$ \\
\hline Buonamici et al., 2007 [2] & 6 & Stent thrombosis & 3.1 \\
\hline \multirow{4}{*}{ Campo et al., 2010 [20] } & \multirow{4}{*}{12} & \multirow{4}{*}{ All-cause death, nonfatal ami, and stroke } & $\begin{array}{c}\text { Full Responder (FR) } \\
8.6\end{array}$ \\
\hline & & & $\begin{array}{l}\text { Poor Responder } \\
\quad(\mathrm{PR}) 15.8\end{array}$ \\
\hline & & & ASA FR 10 PR 13 \\
\hline & & & Clop FR 5.9 PR 17.3 \\
\hline Chiu et al., 2011 [21] & 24 & $\begin{array}{l}\text { Cardiovascular death, nonfatal myocardial infarction, or } \\
\text { nonfatal stroke }\end{array}$ & 10 \\
\hline Collet et al., 2012 [7] & 1 & Stent thrombosis & 2 \\
\hline \multirow{2}{*}{ Cuisset et al., 2006; $300 \mathrm{mg}$ [22] } & \multirow[t]{2}{*}{1} & \multirow{2}{*}{$\begin{array}{l}\text { Cardiovascular death, nonfatal ami, stent thrombosis, and } \\
\text { stroke }\end{array}$} & 12 \\
\hline & & & 33.3 HPR 0.5 NPR \\
\hline \multirow{2}{*}{ Cuisset et al., 2006; $600 \mathrm{mg}$ [22] } & \multirow{2}{*}{1} & \multirow{2}{*}{$\begin{array}{l}\text { Cardiovascular death, nonfatal ami, stent thrombosis, and } \\
\text { stroke }\end{array}$} & 4.1 \\
\hline & & & 27.2 HPR 0.008 NPR \\
\hline \multirow{3}{*}{ Geisler et al., 2006 [23] } & \multirow{3}{*}{3} & \multirow{3}{*}{ Cardiovascular death, nonfatal ami, and nonfatal stroke } & 6.6 \\
\hline & & & $\begin{array}{c}5.6 \text { Adequate } \\
\text { clopidogrel response }\end{array}$ \\
\hline & & & $\begin{array}{l}22.7 \text { Low clopidogrel } \\
\text { response }\end{array}$ \\
\hline \multirow{2}{*}{ Hochholzer et al., 2006 [24] } & \multirow{2}{*}{1} & \multirow{2}{*}{$\begin{array}{l}\text { All-cause death, nonfatal ami, and percutaneous } \\
\text { revascularization }\end{array}$} & 1.9 \\
\hline & & & 3.5 in upper quartile \\
\hline Jin et al., 2013 [25] & 12 & Cardiovascular death, nonfatal ami, and nonfatal stroke & 11 \\
\hline \multirow{3}{*}{ D.-W. Park et al., 2011 [26] } & \multirow{3}{*}{12} & \multirow{3}{*}{ Cardiac death and nonfatal ami } & 1.4 \\
\hline & & & $\begin{array}{l}0.9 \text { Adequate } \\
\text { clopidogrel response }\end{array}$ \\
\hline & & & $\begin{array}{l}2.8 \text { Low clopidogrel } \\
\text { response }\end{array}$ \\
\hline Ko et al., 2011 [27] & 1 & $\begin{array}{l}\text { All-cause death, nonfatal ami, nonfatal stroke, and } \\
\text { percutaneous revascularization }\end{array}$ & 8.6 \\
\hline Marcucci et al., 2012 [28] & 12 & Cardiac death and nonfatal ami & 9.6 \\
\hline \multirow{3}{*}{ Motoda et al., 2012 [29] } & \multirow{3}{*}{12} & Cardiac death, nonfatal ami, stent thrombosis, and target & 12 \\
\hline & & vessel revascularization & 19 in HPR \\
\hline & & & $5.1 \mathrm{in} \mathrm{NPR}$ \\
\hline
\end{tabular}


TABLE 3: Continued.

\begin{tabular}{|c|c|c|c|}
\hline & $\begin{array}{l}\text { Follow-up } \\
\text { (months) }\end{array}$ & Definition of outcome & $\begin{array}{l}\text { Incidence of } \\
\text { outcome }\end{array}$ \\
\hline \multirow{2}{*}{ K. W. Park et al., 2011 [30] } & \multirow{2}{*}{24} & \multirow{2}{*}{$\begin{array}{l}\text { Cardiac death, nonfatal ami, nonfatal stroke, and urgent } \\
\text { percutaneous revascularization }\end{array}$} & 14.6 HPR \\
\hline & & & 8.7 LPR \\
\hline Park et al. (ACS), 2013 [31] & 72 & $\begin{array}{l}\text { Cardiac death, nonfatal ami, nonfatal stroke, urgent } \\
\text { percutaneous revascularization, and stent thrombosis }\end{array}$ & \\
\hline Park et al. (Stable Angina), 2013 [31] & 72 & $\begin{array}{l}\text { Cardiac death, nonfatal ami, nonfatal stroke, urgent } \\
\text { percutaneous revascularization, and stent thrombosis }\end{array}$ & \\
\hline \multirow{4}{*}{ Parodi et al., 2011 [32] } & \multirow{4}{*}{1} & \multirow{4}{*}{$\begin{array}{l}\text { Cardiac death, nonfatal ami and percutaneous } \\
\text { revascularization }\end{array}$} & 3 1st quartile \\
\hline & & & 5 2nd quartile \\
\hline & & & 10 3rd quartile \\
\hline & & & 204 th quartile \\
\hline \multirow{2}{*}{ Patti et al., 2008 [33] } & \multirow{2}{*}{24} & \multirow{2}{*}{ All-cause death, nonfatal ami, unstable angina, and stroke } & 13.3 HAPR \\
\hline & & & 9.9 LAPR \\
\hline \multirow{2}{*}{ Pettersen et al., 2012 [34] } & \multirow{2}{*}{6} & \multirow{2}{*}{$\begin{array}{l}\text { Cardiovascular death, nonfatal myocardial infarction, and } \\
\text { stent thrombosis }\end{array}$} & $6.5 \mathrm{HPR}$ \\
\hline & & & $1 \mathrm{LPR}$ \\
\hline \multirow{2}{*}{ Price et al., 2011 [9] } & \multirow{2}{*}{1} & \multirow{2}{*}{ Stent thrombosis } & $2.2 \mathrm{HPR}$ \\
\hline & & & $0.2 \mathrm{LPR}$ \\
\hline Saia et al., 2013 [35] & 12 & $\begin{array}{l}\text { All-cause death, ami, and urgent target vessel } \\
\text { revascularization }\end{array}$ & \\
\hline \multirow{3}{*}{ Sibbing et al., 2009 [36] } & \multirow{3}{*}{1} & \multirow{3}{*}{$\begin{array}{l}\text { All-cause death, ami, and urgent target vessel } \\
\text { revascularization }\end{array}$} & $\begin{array}{l}\text { Abciximab/UFH: } 9.4 \\
\text { HPR 6.7 LPR }\end{array}$ \\
\hline & & & Bivalirudin: 22.0 \\
\hline & & & HPR 5.0 LPR \\
\hline \multirow{4}{*}{ Sibbing et al., 2012 [37] } & \multirow{4}{*}{12} & \multirow{4}{*}{$\begin{array}{l}\text { Acute coronary syndrome, stent thrombosis, stroke, death, } \\
\text { and revascularization }\end{array}$} & $37.5 \mathrm{DHPR}$ \\
\hline & & & $33.3 \mathrm{HCPR}$ \\
\hline & & & 25.6 HAPR \\
\hline & & & 18.6 LPR \\
\hline \multicolumn{2}{|l|}{ Siller-Matula et al., 2013 [38] } & $\begin{array}{l}\text { Acute coronary syndrome, stent thrombosis, stroke, death, } \\
\text { and revascularization }\end{array}$ & \\
\hline \multirow{3}{*}{ Stone et al., 2013 [39] } & \multirow{3}{*}{24} & \multirow{3}{*}{$\begin{array}{l}\text { All-cause death and myocardial infarction and stent } \\
\text { thrombosis }\end{array}$} & 2.4 death \\
\hline & & & $3.9 \mathrm{mi}$ \\
\hline & & & $1.3 \mathrm{ST}$ \\
\hline
\end{tabular}

missing counterparts at the pooled estimate, and evaluating the adjusted confidence interval [14]).

\section{Discussion}

The main results of the present meta-analysis, investigating incidence and impact of HOPR on prognosis, are as follows: (a) HOPR represents a frequent finding for patients with coronary artery disease, both in chronic and acute settings; (b) current evidence is limited from relevant publication bias; (c) after adjustment for clinical and methodological confounders HOPR appraised for "all comers" with CAD does not significantly increase the hazard of adverse cardiac events; and (d) usefulness in high-risk patients may not be excluded and remains to be assessed.

Many reasons can explain nonresponsiveness to antiplatelet medications, such as interindividual variability in the metabolism of clopidogrel (which is a prodrug activated by CYP-3A4, CYP-2C19, and CYP1A2), drug-drug interactions (i.e., interaction on the same metabolic pathway for clopidogrel, but also competition for binding sites on COX-1 by nonsteroidal anti-inflammatory medications and aspirin), P2Y12 receptor polymorphisms and increased platelet turnover during inflammation, acute coronary events, and diabetes mellitus. Interestingly, conventional cardiovascular risk factors themselves (smoking, diabetes, and hyperlipidemia) and also the same clinical pattern of unstable angina, increasing macrophage's thromboxane synthesis, enhance resistance to aspirin [40].

Previously, numerous observational studies have demonstrated the causal relationship between laboratory evidence of nonresponsiveness to aspirin or clopidogrel and an increase hazard of death, myocardial reinfarction, and stent thrombosis during secondary prevention for coronary disease $[18,19$, 


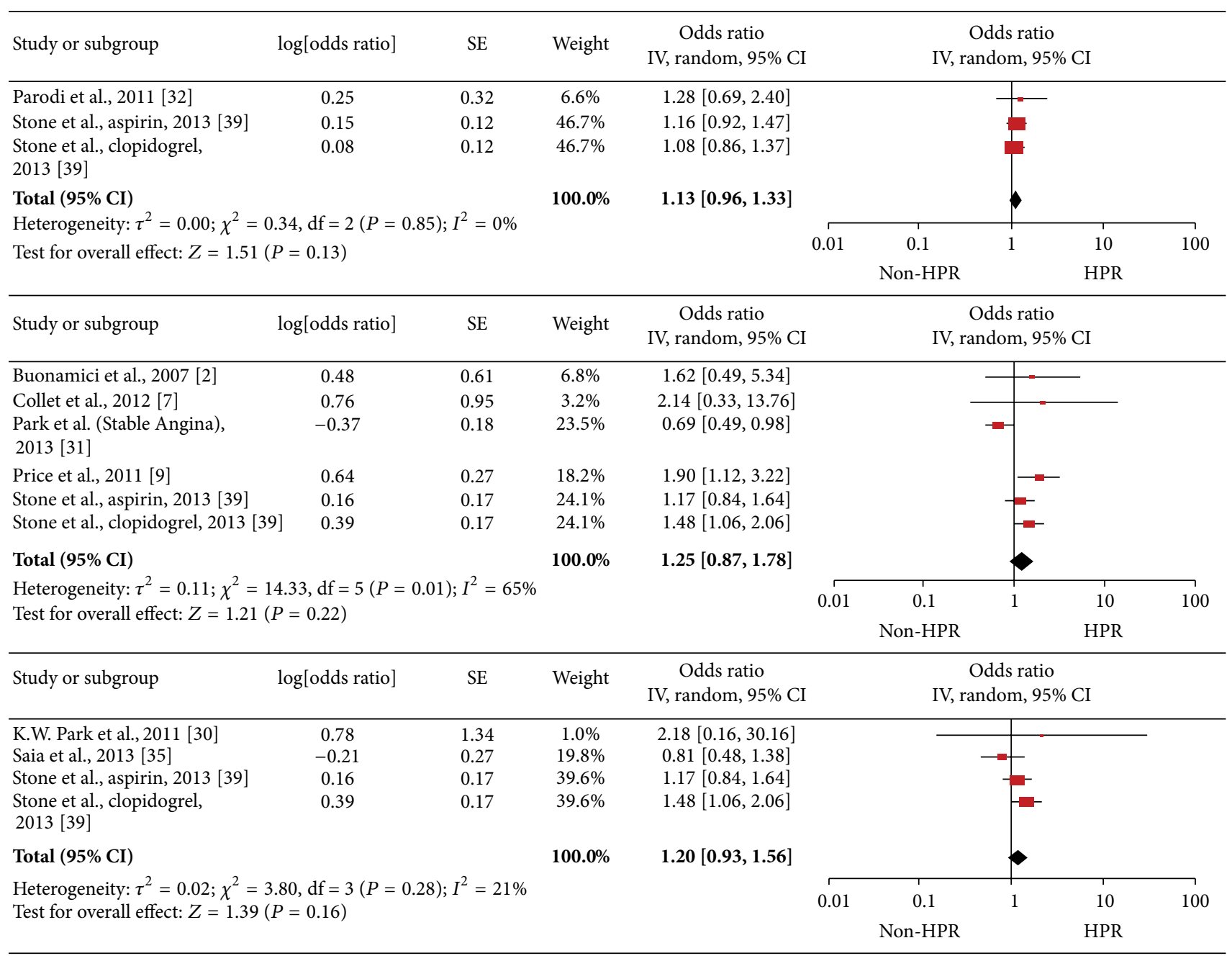

Figure 3: Pooled analysis of odds ratio according to end point (all-cause death [19099 patients], stent thrombosis [25848 patients] and clinically relevant bleeding [19472 patients] from above to below).

23, 41-43]. The obvious induction was that individualization of antiplatelet therapy based on laboratory tests should improve outcomes, even if most of these studies were limited by absence of multivariate adjustments, that is, without a global assessment of potential clinical confounders [19], for example, the presence of diabetes, which increases both HOPR and recurrent cardiac events after ACS.

However, subsequent randomized controlled trials questioned this hypothesis. In the ARMYDA-2 study, pretreatment with a $600 \mathrm{mg}$ loading dose of clopidogrel given before PCI was demonstrated to be safe and, as compared with the 300-mg dose, reduced periprocedural MI without increased bleeding [44]. On the other hand, the GRAVITAS and the ARCTIC trials, which randomized patients with HOPR after PCI with drug eluting stents to high-dose clopidogrel compared with standard-dose, did not showe significant improvements in clinical outcomes [22, 33]. Later, new evidence suggested that a more tailored therapy could be attained by switching to newer drugs $[9,45,46]$. Similarly, randomized evidence failed to demonstrate a clinical impact. The TRIGGER-PCI study showed that HOPR after elective PCI with DES implantation, if detected, can be reliably corrected by switching from clopidogrel to prasugrel but again failed to demonstrate an improvement in clinical outcomes [47]. A similar result emerged from the TRILOGY-ACS trial, randomizing patients with NSTE-ACS who were medically managed [48]. More recently, switching to ticagrelor seems to be associated to an effective reduction in HOPR but studies about the effective clinical impact are still lacking [47, 49].

This meta-analysis indicates that HOPR does not seem to be a useful predictor of outcomes in an "all comers" CAD population. These results hold true both for overall studies, and, after appraisal for diagnosis, types of antiplatelet medication analysed and assays were exploited. These findings may be explained because they derive from data drawn from multivariate analysis, with a critical adjustment (even though limited by absence of randomization itself) for 


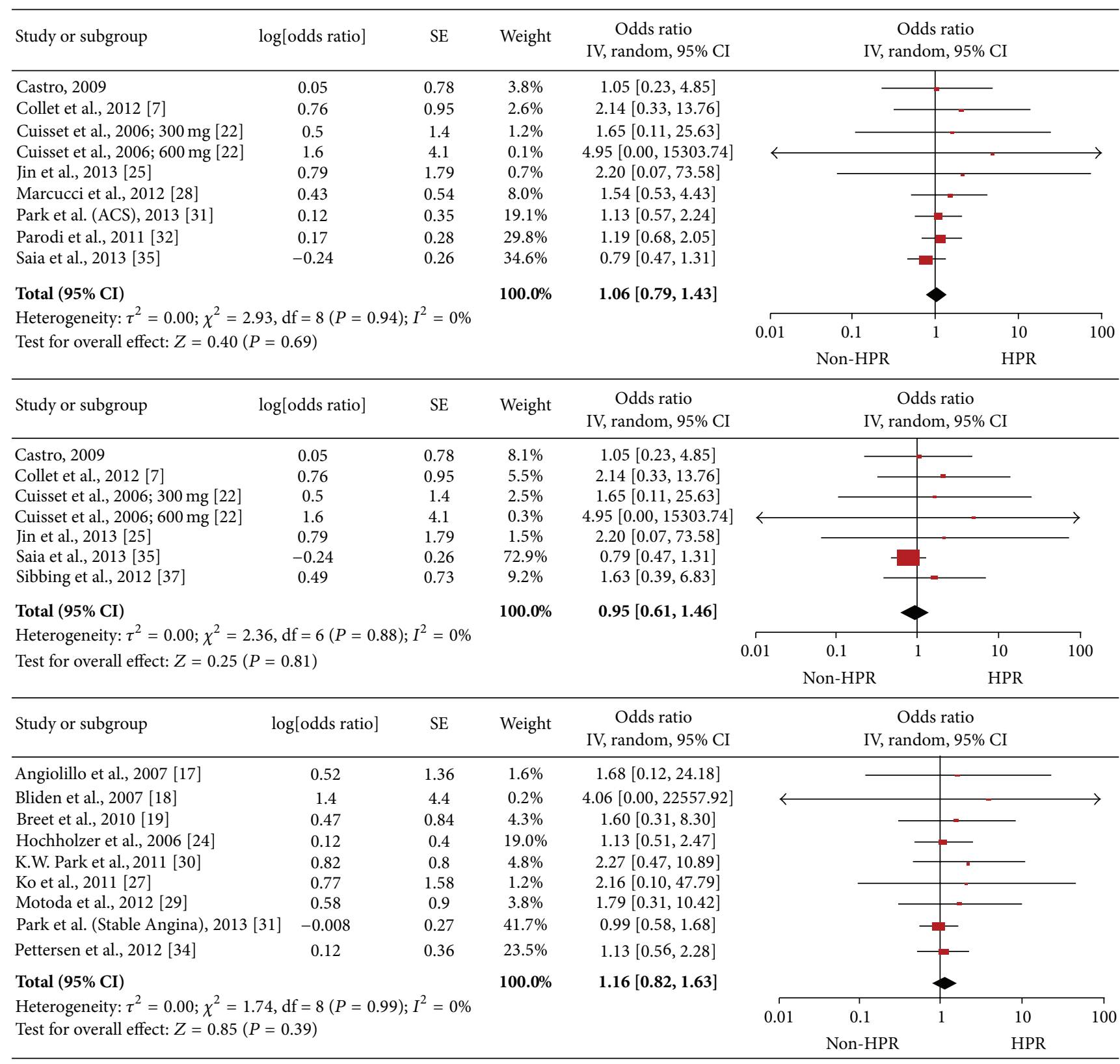

FIGURE 4: Pooled analysis of odds ratio for platelet reactivity according to diagnosis (ACS [3103 patients], acute myocardial infarction [2189 patients], stable angina [4487 patients] from above to below).

clinical features both increasing platelet resistance and risk of adverse events (like diabetes mellitus, smoking, or renal disease).

While HOPR should not totally be disregarded, a focus on high-risk patients seems more appropriate [49-53], for example, those with recurrent stent thrombosis in the absence of periprocedural or adherence problems or in diabetic or in HIV populations who have a well-known increased risk of recurrent events.

Current evidence remains burdened from relevant publication bias, which deeply affects clinical interpretation of HOPR. This phenomenon was described by psychologist Robert Rosenthal as the "file drawer problem"; he wrote that "journals are filled with the $5 \%$ of the studies that show Type I errors, while the file drawers are filled with the $95 \%$ of the studies that show nonsignificant results" [54]. In the cardiovascular field, this problem was recently demonstrated by Ioannidis and colleagues [55], who stated that, among 56 meta-analyses reporting relationships between biomarkers and cardiovascular events, only 13 were not affected by selection bias. However, most of current guidelines do not include this kind of evaluation, which may deeply influence every day clinical decisions.

Our analysis has some limitations, including a great number of observational studies, which brings incomplete data around follow-up and about the correct reporting of adverse 


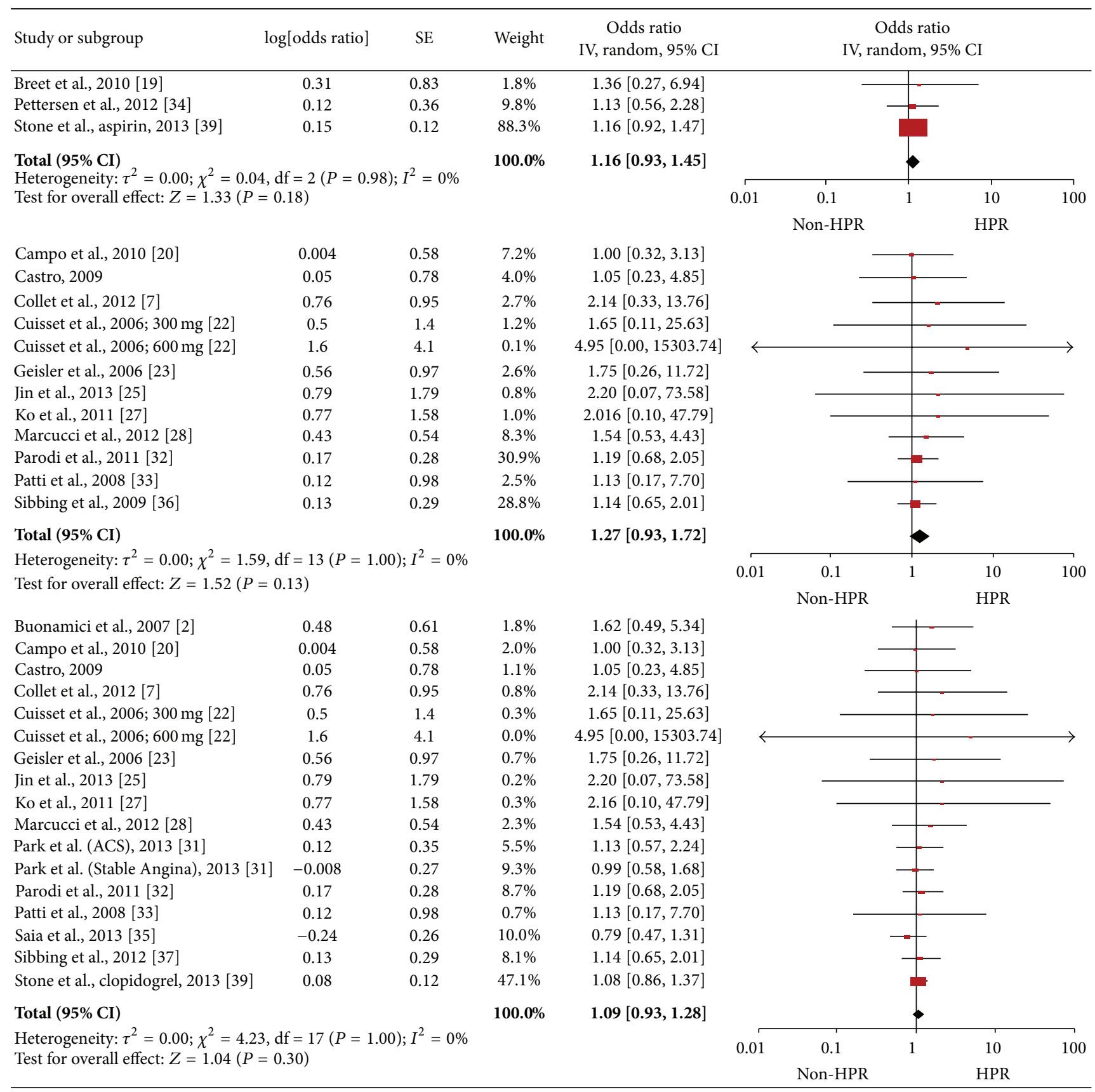

FIGURE 5: Pooled analysis of odds ratio according to reactivity (aspirin: 10066 patients; ADR receptor antagonists: 6750 patients; both: 17436 patients, from above to below in Figure 5).

effects, different definitions, and outcomes. Moreover, for each sensitivity analysis, the number of patients was inferior to that of overall population, although superior or similar to that of previous meta-analysis on this topic [3, 4]. Again, just a small number of studies could reliably monitor compliance. Platelet reactivity tests differed in each study, which also limits the HOPR definition. Because of the selection criteria, no studies selected use the Platelet Vasodilator-Stimulated Phosphorylation test (PLT-VASP test), a flow cytometry test that is today the most specific test to assess the effect of the platelet P2Y12 antagonists (clopidogrel, ticlopidine, and prasugrel) [51]. Thus, the included studies' quality was evaluated according to standardized criteria and we separately abstracted and appraised study design, setting, and data source, as well as risk of analytical, selection, adjudication, detection, and attrition bias. For all studies, publication bias was formally assessed. After adjusting for this bias, HOPR did not significantly increase adverse cardiac events for all studies.

We therefore conclude that routine assessment of HOPR is not useful, but high-risk subsets of patients (i.e., diabetics, multiple cardiovascular risk factors, and important 


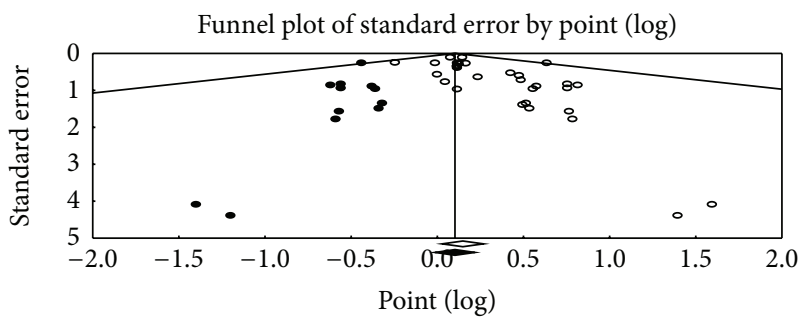

(a)

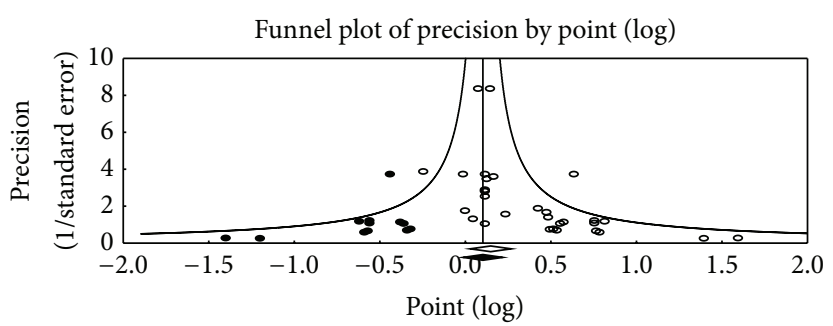

(b)

FiguRE 6: Funnel plot of standard error (a) and of precision (b). White box: observed studies. Black box: imputed study (trim and fill methods evaluates publication bias by evaluating number of "asymmetric" trials on the right side, removing and replacing them with missing counterparts at the pooled estimate and evaluating the adjusted confidence interval).

comorbidities, especially if they need therapies potentially interacting with antiplatelet drugs) may potentially benefit from its assessment and interpretations remain to be assessed.

\section{Abbreviations}

ACS: Acute coronary syndrome

AMI: Acute myocardial infarction

HOPR: High on-treatment platelet reactivity

PCI: Percutaneous coronary intervention.

\section{Conflict of Interests}

The authors declare that there is no conflict of interests regarding the publication of this paper.

\section{Authors' Contribution}

Fabrizio D’Ascenzo conceived the project and Giuseppe Biondi Zoccai performed the analysis. All the other authors were involved in the writing and the preparation of the paper.

\section{References}

[1] EAPCI, W. Wijns, P. Kolh et al., "Guidelines on myocardial revascularization: the Task Force on Myocardial Revascularization of the European Society of Cardiology (ESC) and the European Association for Cardio-Thoracic Surgery (EACTS)," European Heart Journal, vol. 31, pp. 2501-2555, 2010.

[2] P. Buonamici, R. Marcucci, A. Migliorini et al., "Impact of platelet reactivity after clopidogrel administration on drugeluting stent thrombosis," Journal of the American College of Cardiology, vol. 49, pp. 2312-2317, 2007.

[3] F. D’Ascenzo, F. Colombo, U. Barbero et al., "Discontinuation of dual antiplatelet therapy over 12 months after acute coronary syndromes increases risk for adverse events in patients treated with percutaneous coronary intervention: systematic review and meta-analysis," Journal of Interventional Cardiology, vol. 27, no. 3, pp. 233-241, 2014.

[4] G. Quadri, F. D’Ascenzo, M. Bollati et al., "Diffuse coronary disease: short- and long-term outcome after percutaneous coronary intervention," Acta Cardiologica, vol. 68, no. 2, pp. 151160, 2013.
[5] D. Aradi, A. Komócsi, A. Vorobcsuk et al., "Prognostic significance of high on-clopidogrel platelet reactivity after percutaneous coronary intervention: systematic review and metaanalysis," American Heart Journal, vol. 160, no. 3, pp. 543-551, 2010.

[6] S. S. Brar, J. ten Berg, R. Marcucci et al., "Impact of platelet reactivity on clinical outcomes after percutaneous coronary intervention. A collaborative meta-analysis of individual participant data," Journal of the American College of Cardiology, vol. 58, no. 19, pp. 1945-1954, 2011.

[7] J. P. Collet, T. Cuisset, G. Rangé et al., "Bedside monitoring to adjust antiplatelet therapy for coronary stenting," The New England Journal of Medicine, vol. 367, pp. 2100-2109, 2012.

[8] D. Trenk, G. W. Stone, M. Gawaz et al., "A randomized trial of prasugrel versus clopidogrel in patients with high platelet reactivity on clopidogrel after elective percutaneous coronary intervention with implantation of drug-eluting stents: results of the TRIGGER-PCI (Testing Platelet Reactivity In Patients Undergoing Elective Stent Placement on Clopidogrel to Guide Alternative Therapy With Prasugrel) study," Journal of the American College of Cardiology, vol. 59, no. 24, pp. 2159-2164, 2012.

[9] M. J. Price, P. B. Berger, P. S. Teirstein et al., "Standard- vs highdose clopidogrel based on platelet function testing after percutaneous coronary intervention: the GRAVITAS randomized trial," Journal of the American Medical Association, vol. 305, pp. 1097-1105, 2011.

[10] D. Aradi, A. Komócsi, M. J. Price et al., "Efficacy and safety of intensified antiplatelet therapy on the basis of platelet reactivity testing in patients after percutaneous coronary intervention: systematic review and meta-analysis," International Journal of Cardiology, vol. 167, no. 5, pp. 2140-2148, 2012.

[11] G. Biondi-Zoccai, P. Agostoni, A. Abbate, F. D’Ascenzo, and M. G. Modena, "Potential pitfalls of meta-analyses of observational studies in cardiovascular research," Journal of the American College of Cardiology, vol. 59, no. 3, pp. 292-293, 2012.

[12] D. Moher, D. J. Cook, S. Eastwood, I. Olkin, D. Rennie, and D. F. Stroup, "Improving the quality of reports of meta-analyses of randomised controlled trials: the QUOROM statement," The Lancet, vol. 354, no. 9193, pp. 1896-1900, 1999.

[13] D. F. Stroup, J. A. Berlin, S. C. Morton et al., "Meta-analysis of observational studies in epidemiology: a proposal for reporting. Meta-Analysis of Observational Studies in Epidemiology (MOOSE) group," Journal of the American Medical Association, vol. 283, pp. 2008-2012, 2000.

[14] M. E. Bertrand, M. L. Simoons, K. A. Fox et al., "Management of acute coronary syndromes in patients presenting without 
persistent ST-segment elevation," European Heart Journal, vol. 23, no. 23, pp. 1809-1840, 2002.

[15] J. P. T. Higgins and S. Green, Cochrane Handbook for Systematic Reviews of Interventions Version 5.0.2, The Cochrane Collaboration, 2009, http://handbook.cochrane.org/.

[16] A. J. Sutton, S. J. Duval, R. L. Tweedie, K. R. Abrams, and D. R. Jones, "Empirical assessment of effect of publication bias on meta-analyses," The British Medical Journal, vol. 320, no. 7249, pp. 1574-1577, 2000.

[17] D. J. Angiolillo, E. Bernardo, M. Sabaté et al., "Impact of platelet reactivity on cardiovascular outcomes in patients with type 2 diabetes mellitus and coronary artery disease," Journal of the American College of Cardiology, vol. 50, no. 16, pp. 1541-1547, 2007.

[18] K. P. Bliden, J. DiChiara, U. S. Tantry, A. K. Bassi, S. K. Chaganti, and P. A. Gurbel, "Increased risk in patients with high platelet aggregation receiving chronic clopidogrel therapy undergoing percutaneous coronary intervention: is the current antiplatelet therapy adequate?" Journal of the American College of Cardiology, vol. 49, no. 6, pp. 657-666, 2007.

[19] N. J. Breet, J. W. van Werkum, H. J. Bouman et al., "Comparison of platelet function tests in predicting clinical outcome in patients undergoing coronary stent implantation," Journal of the American Medical Association, vol. 303, pp. 754-762, 2010.

[20] G. Campo, L. Fileti, N. de Cesare et al., "Long-term clinical outcome based on aspirin and clopidogrel responsiveness status after elective percutaneous coronary intervention: a 3T/2R (Tailoring Treatment with Tirofiban in Patients Showing Resistance to Aspirin and/or resistance to Clopidogrel) trial substudy," Journal of the American College of Cardiology, vol. 56, no. 18, pp. 1447-1455, 2010.

[21] F. C. Chiu, T. D. Wang, J. K. Lee et al., "Residual platelet reactivity after aspirin and clopidogrel treatment predicts 2year major cardiovascular events in patients undergoing percutaneous coronary intervention," European Journal of Internal Medicine, vol. 22, no. 5, pp. 471-477, 2011.

[22] T. Cuisset, C. Frere, J. Quilici et al., "Benefit of a 600-mg loading dose of clopidogrel on platelet reactivity and clinical outcomes in patients with non-ST-segment elevation acute coronary syndrome undergoing coronary stenting," Journal of the American College of Cardiology, vol. 48, no. 7, pp. 1339-1345, 2006.

[23] T. Geisler, H. Langer, M. Wydymus et al., "Low response to clopidogrel is associated with cardiovascular outcome after coronary stent implantation," European Heart Journal, vol. 27, pp. 2420-2425, 2006.

[24] W. Hochholzer, D. Trenk, H.-P. Bestehorn et al., "Impact of the degree of peri-interventional platelet inhibition after loading with clopidogrel on early clinical outcome of elective coronary stent placement," Journal of the American College of Cardiology, vol. 48, no. 9, pp. 1742-1750, 2006.

[25] H.-Y. Jin, T.-H. Yang, D.-I. Kim et al., "High post-clopidogrel platelet reactivity assessed by a point-of-care assay predicts long-term clinical outcomes in patients with ST-segment elevation myocardial infarction who underwent primary coronary stenting," International Journal of Cardiology, vol. 167, no. 5, pp. 1877-1881, 2013.

[26] D.-W. Park, S.-W. Lee, S.-C. Yun et al., "A point-of-care platelet function assay and C-reactive protein for prediction of major cardiovascular events after drug-eluting stent implantation," Journal of the American College of Cardiology, vol. 58, no. 25, pp. 2630-2639, 2011.
[27] Y.-G. Ko, J.-W. Suh, B. H. Kim et al., "Comparison of 2 pointof-care platelet function tests, VerifyNow Assay and Multiple Electrode Platelet Aggregometry, for predicting early clinical outcomes in patients undergoing percutaneous coronary intervention," American Heart Journal, vol. 161, no. 2, pp. 383-390, 2011.

[28] R. Marcucci, B. Giusti, R. Paniccia, A. M. Gori, and C. Saracini, "High on-treatment platelet reactivity by ADP and increased risk of MACE in good clopidogrel metabolizers," Platelets, vol. 23, no. 8, pp. 586-593, 2012.

[29] C. Motoda, H. Ueda, Y. Hayashi et al., "Impact of platelet reactivity to adenosine diphosphate before implantation of drug-eluting stents on subsequent adverse cardiac events in patients with stable angina," Circulation Journal, vol. 76, no. 3, pp. 641-649, 2012.

[30] K. W. Park, K. H. Jeon, S. H. Kang et al., "Clinical outcomes of high on-treatment platelet reactivity in Koreans receiving elective percutaneous coronary intervention (from results of the CROSS VERIFY study)," American Journal of Cardiology, vol. 108, no. 11, pp. 1556-1563, 2011.

[31] D.-W. Park, J.-M. Ahn, H.-G. Song et al., "Differential prognostic impact of high on-treatment platelet reactivity among patients with acute coronary syndromes versus stable coronary artery disease undergoing percutaneous coronary intervention," American Heart Journal, vol. 165, no. 1, pp. 34.e1-42.el, 2013.

[32] G. Parodi, R. Marcucci, R. Valenti, A. M. Gori, and A. Migliorini, "High residual platelet reactivity after clopidogrel loading and long-term cardiovascular events among patients with acute coronary syndromes undergoing PCI," JAMA-Journal of the American Medical Association, vol. 306, no. 11, pp. 1215-1223, 2011.

[33] G. Patti, A. Nusca, F. Mangiacapra, L. Gatto, A. D’Ambrosio, and G. Di Sciascio, "Point-of-care measurement of clopidogrel responsiveness predicts clinical outcome in patients undergoing percutaneous coronary intervention: results of the ARMYDAPRO (Antiplatelet therapy for Reduction of MYocardial Damage during Angioplasty-Platelet Reactivity Predicts Outcome) study," Journal of the American College of Cardiology, vol. 52, no. 14, pp. 1128-1133, 2008.

[34] A. Å. Pettersen, I. Seljeflot, M. Abdelnoor, and H. Arnesen, "High on-Aspirin platelet reactivity and clinical outcome in patients with stable coronary artery disease: results from ASCET (Aspirin Nonresponsiveness and Clopidogrel Endpoint Trial)," The American Heart Association, vol. 1, no. 3, Article ID e000703, 2012.

[35] F. Saia, M. Marino, G. Campo et al., "Incidence and outcome of high on-treatment platelet reactivity in patients with non-st elevation acute coronary syndromes undergoing percutaneous coronary intervention (from the VIP [verify now and inhibition of platelet reactivity] study)," American Journal of Cardiology, vol. 112, no. 6, pp. 792-798, 2013.

[36] D. Sibbing, S. Braun, T. Morath et al., "Platelet reactivity after clopidogrel treatment assessed with point-of-care analysis and early drug-eluting stent thrombosis," Journal of the American College of Cardiology, vol. 53, no. 10, pp. 849-856, 2009.

[37] D. Sibbing, I. Bernlochner, S. Schulz et al., "Prognostic value of a high on-clopidogrel treatment platelet reactivity in bivalirudin versus abciximab treated non-ST-segment elevation myocardial infarction patients: ISAR-REACT 4 (Intracoronary stenting and antithrombotic regimen: rapid early action for coronary treatment-4) platelet substudy," Journal of the American College of Cardiology, vol. 60, no. 5, pp. 369-377, 2012. 
[38] J. M. Siller-Matula, G. Delle-Karth, G. Christ et al., "Dual nonresponsiveness to antiplatelet treatment is a stronger predictor of cardiac adverse events than isolated non-responsiveness to clopidogrel or aspirin," International Journal of Cardiology, vol. 167, no. 2, pp. 430-435, 2013.

[39] G. W. Stone, B. Witzenbichler, G. Weisz et al., "Platelet reactivity and clinical outcomes after coronary artery implantation of drug-eluting stents (ADAPT-DES): a prospective multicentre registry study," The Lancet, vol. 382, no. 9892, pp. 614-623, 2013.

[40] C. E. Tourmousoglou and C. K. Rokkas, "Clopidogrel and aspirin in cardiovascular medicine: Responders or not-current best available evidence," Cardiovascular \& Hematological Agents in Medicinal Chemistry, vol. 6, no. 4, pp. 312-322, 2008.

[41] M. J. Price, S. Endemann, R. R. Gollapudi et al., "Prognostic significance of post-clopidogrel platelet reactivity assessed by a point-of-care assay on thrombotic events after drug-eluting stent implantation," European Heart Journal, vol. 29, no. 8, pp. 992-1000, 2008.

[42] T. Cuisset, C. Frere, J. Quilici et al., "High post-treatment platelet reactivity identified low-responders to dual antiplatelet therapy at increased risk of recurrent cardiovascular events after stenting for acute coronary syndrome," Journal of Thrombosis and Haemostasis, vol. 4, pp. 542-549, 2006.

[43] R. Marcucci, A. M. Gori, R. Paniccia et al., "Cardiovascular death and nonfatal myocardial infarction in acute coronary syndrome patients receiving coronary stenting are predicted by residual platelet reactivity to ADP detected by a point-of-care assay: a 12-month follow-up," Circulation, vol. 119, no. 2, pp. 237242, 2009.

[44] G. Biondi-Zoccai, P. Agostoni, A. Abbate, F. D’Ascenzo, and M. G. Modena, "Potential pitfalls of meta-analyses of observational studies in cardiovascular research," Journal of the American College of Cardiology, vol. 59, no. 3, pp. 292-293, 2012.

[45] F. D’Ascenzo, U. Barbero, and C. Moretti, "Percutaneous coronary intervention versus coronary artery bypass graft for stable angina: meta-regression of randomized trials," Contemporary Clinical Trials, vol. 38, no. 1, pp. 51-58, 2014.

[46] D. Alexopoulos, K. C. Theodoropoulos, E. F. Stavrou et al., "Prasugrel versus high dose clopidogrel to overcome early high on clopidogrel platelet reactivity in patients with ST elevation myocardial infarction," Cardiovascular Drugs and Therapy, vol. 26, pp. 393-400, 2012.

[47] D. Trenk, G. W. Stone, M. Gawaz et al., "A randomized trial of prasugrel versus clopidogrel in patients withHigh on-treatment Platelet reactivity on clopidogrel after elective percutaneous coronary intervention with implantation of drug-eluting stents: results of the TRIGGER-PCI (Testing Platelet Reactivity In Patients Undergoing Elective Stent Placement on Clopidogrel to Guide Alternative Therapy With Prasugrel) study," Journal of the American College of Cardiology, vol. 59, no. 24, pp. 2159-2164, 2012.

[48] M. T. Roe, P. W. Armstrong, K. A. Fox et al., "Prasugrel versus clopidogrel for acute coronary syndromes without revascularization," The New England Journal of Medicine, vol. 367, pp. 12971309, 2012.

[49] M. Almalla, J. Schröder, V. Hennings, N. Marx, and R. Hoffmann, "Long-term outcome after angiographically proven coronary stent thrombosis," The American Journal of Cardiology, vol. 111, no. 9, pp. 1289-1294, 2013.

[50] F. D’Ascenzo, E. Cerrato, G. Biondi-Zoccai et al., "Acute coronary syndromes in human immunodeficiency virus patients: a meta-analysis investigating adverse event rates and the role of antiretroviral therapy," European Heart Journal, vol. 33, no. 7, pp. 875-880, 2012.

[51] F. D’Ascenzo, G. Quadri, E. Cerrato et al., "A meta-analysis investigating incidence and features of stroke in HIV-infected patients in the highly active antiretroviral therapy era," Journal of Cardiovascular Medicine, 2014.

[52] F. D’Ascenzo, M. Bollati, F. Clementi et al., "Incidence and predictors of coronary stent thrombosis: evidence from an international collaborative meta-analysis including 30 studies, 221,066 patients, and 4276 thromboses," International Journal of Cardiology, vol. 167, no. 2, pp. 575-584, 2013.

[53] D. J. Angiolillo, "Antiplatelet therapy in type 2 diabetes mellitus," Current Opinion in Endocrinology, Diabetes and Obesity, vol. 14, pp. 124-131, 2007.

[54] R. Rosenthal, "The file drawer problem and tolerance for null results," Psychological Bulletin, vol. 86, no. 3, pp. 638-641, 1979.

[55] I. Tzoulaki, K. C. Siontis, E. Evangelou, and J. P. A. Ioannidis, "Bias in associations of emerging biomarkers with cardiovascular disease," The JAMA Internal Medicine, vol. 173, no. 8, pp. 664-671, 2013. 


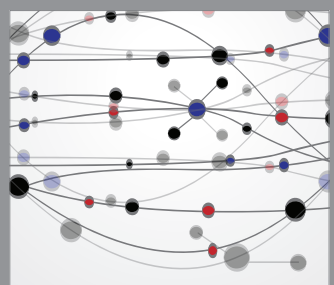

The Scientific World Journal
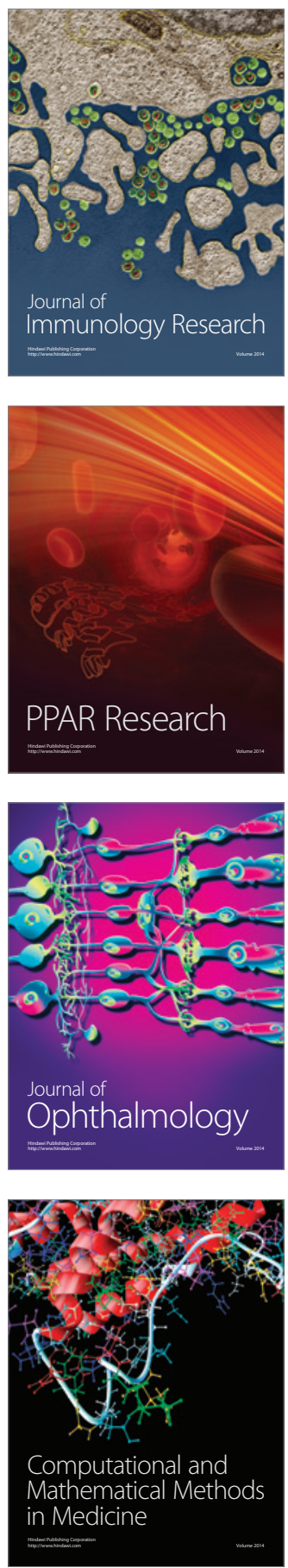

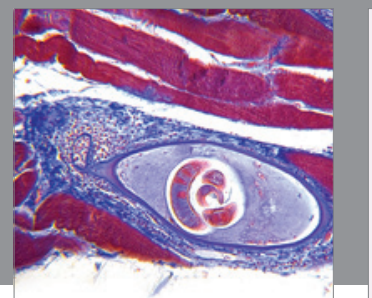

Gastroenterology

Research and Practice
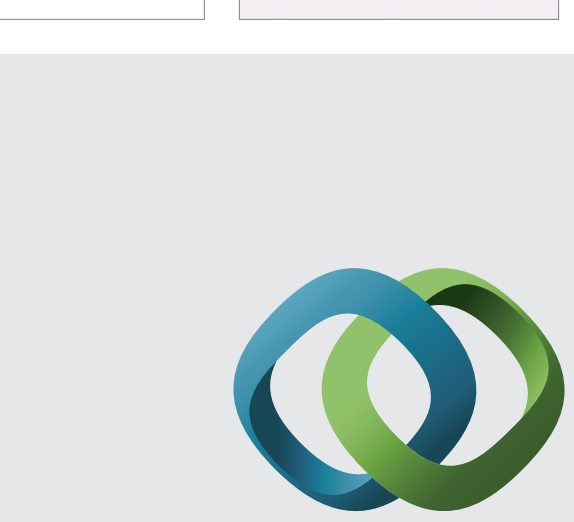

\section{Hindawi}

Submit your manuscripts at

http://www.hindawi.com
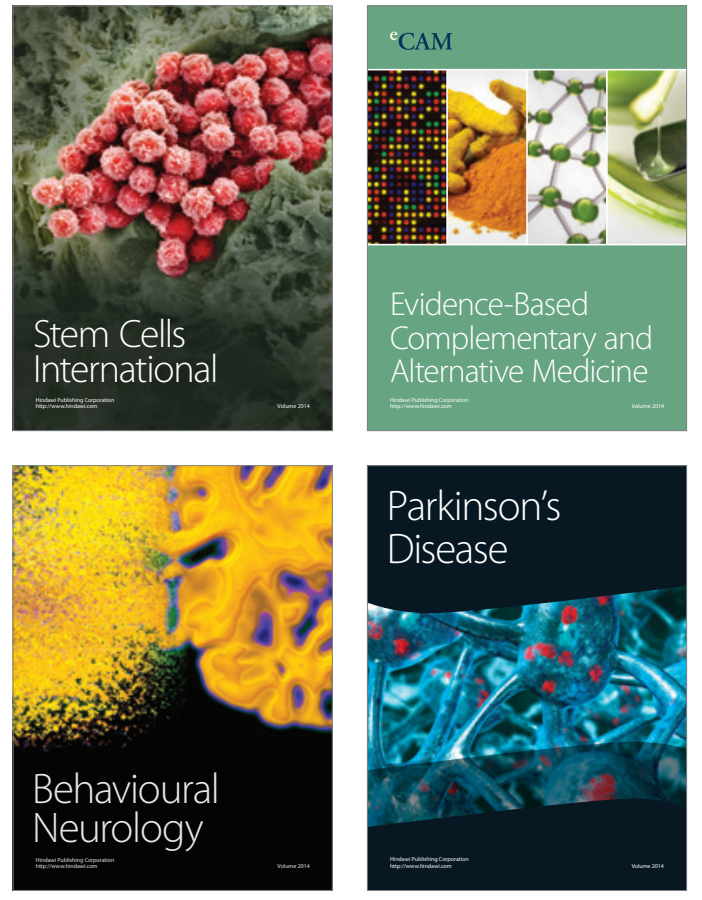
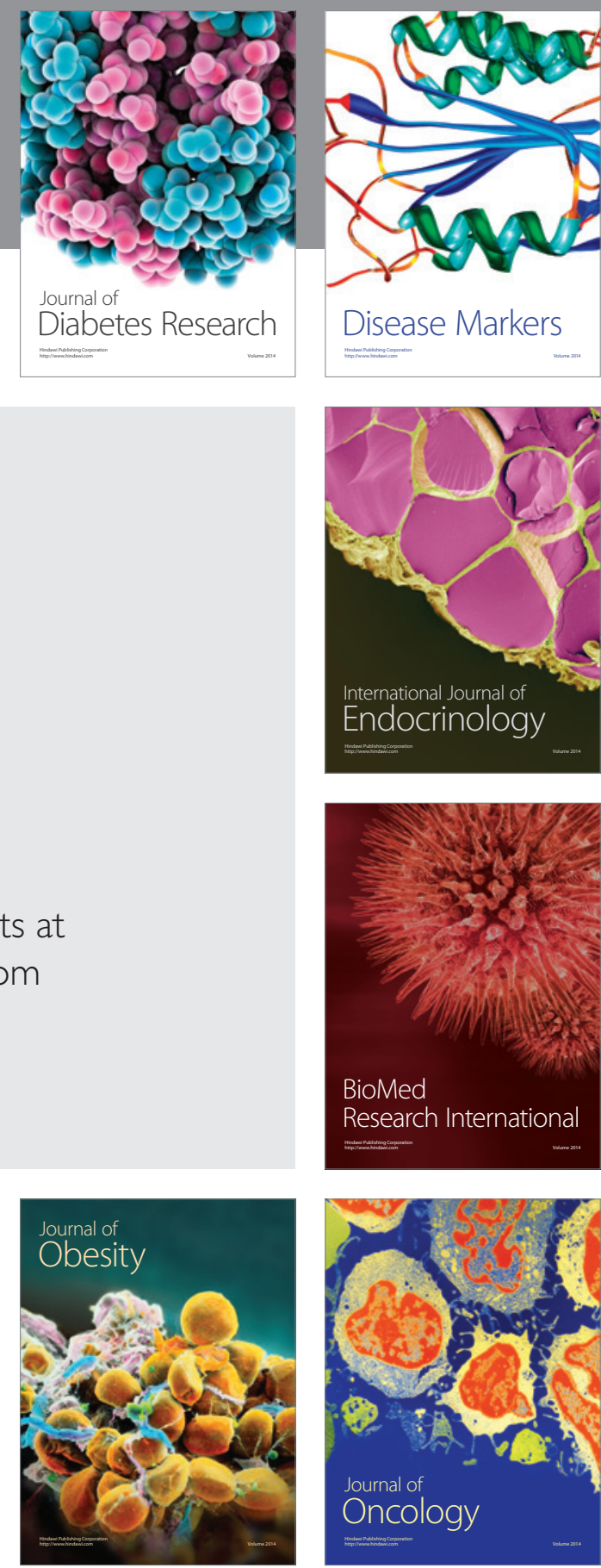

Disease Markers
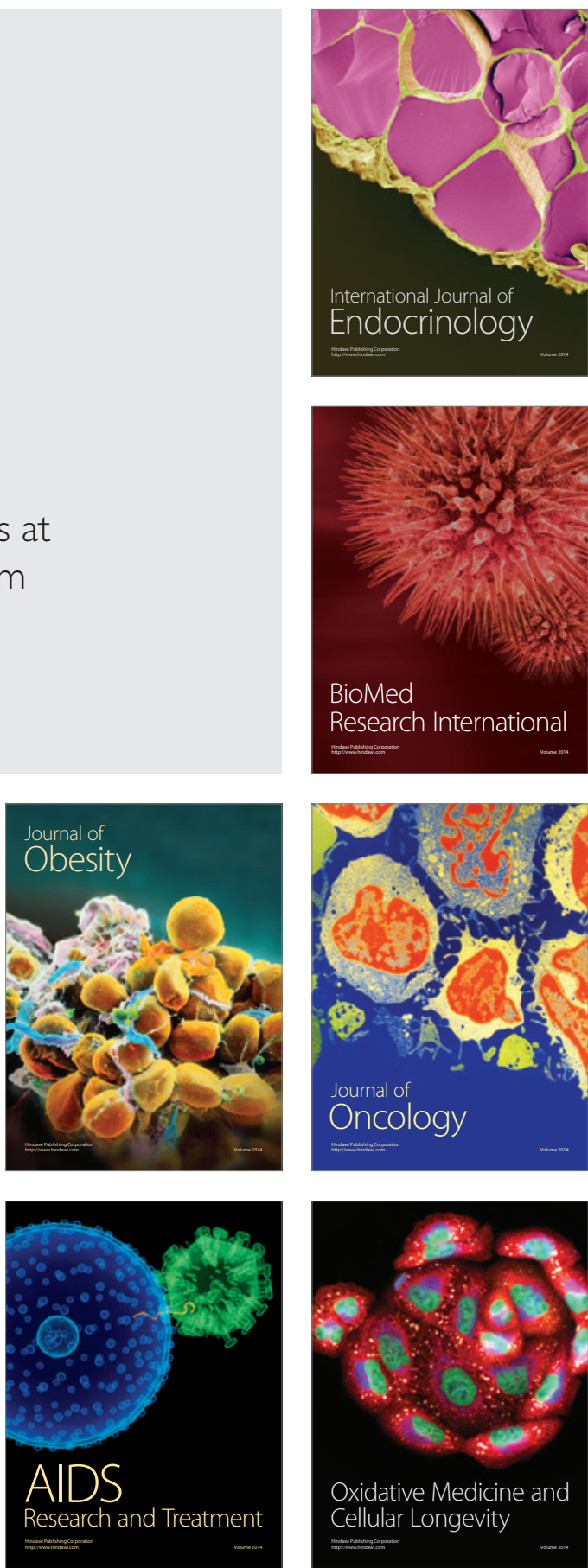